\title{
Avaliação de Cards em Posts de Rede Social Facebook para Campanha Educativa da Prevenção de Sarampo
}

\section{Evaluation of Cards in Facebook Social Network Posts for Education Campaign to Measles Prevention}

\author{
Susana Nogueira Diniz*abc; Sílvia Nunes Rodrigues ${ }^{\mathrm{a}}$
}

\begin{abstract}
${ }^{a}$ Universidade Anhanguera de São Paulo, Programa de Pós-Graduação Stricto Sensu em Ensino de Ciências e Saúde. SP, Brasil. bUniversidade Anhanguera de São Paulo, Programa de Pós-Graduação Stricto Sensu em Biotecnologia e Inovação em Saúde. SP, Brasil 'Universidade Anhanguera de São Paulo, Programa de Pós-Graduação Stricto Sensu em Farmácia. SP, Brasil. *E-mail: dinizsusana@gmail.com
\end{abstract}

\begin{abstract}
Resumo
Este estudo foi motivado pela epidemia de sarampo ocorrida no país, sobretudo, no Estado e na cidade de São Paulo, em função do movimento antivacinas e a reintrodução do vírus do sarampo circulante oriundo de viajantes vindos da Europa, EUA e imigrantes venezuelanos. Inúmeras ações foram implementadas pelos Governos municipais, estaduais e federal, mas até o momento não se observou a diminuição da incidência de novos casos, sugerindo que estas táticas ainda precisam ser aprimoradas. Neste estudo foram avaliadas estratégias de Educação em Saúde, por meio das redes sociais como forma rápida de transmissão de informações sobre as doenças infectocontagiosas e de prevenção pela vacinação. A análise de materiais educativos digitais (cards) publicados no facebook pelos órgãos oficiais: Conselho Nacional de Justiça e Ministério da Saúde, Secretaria de Saúde do Estado de São Paulo, Secretaria de Saúde da Cidade de São Paulo, foi realizada em cinco posts escolhidos entre os órgãos anteriormente citados. Trata-se de uma pesquisa qualitativa que segue o método da pesquisa documental, segundo Lüdke; André, que utilizou como referencial teórico a tipologia de análise de conteúdos, segundo Zabala. Os resultados mostram a predominância de conteúdos de aprendizagem factuais, que correspondem ao conhecimento de fatos, de acontecimentos, de situações, de dados e de fenômenos concretos e singulares facilmente memorizados. Observa-se ainda que as estratégias são regionais, o que pode estar associado à extensão territorial da federação, o que parece indicar a importância de elaborar cards de aprendizagem de conteúdos atitudinais, uma vez que esses favorecem o agrupamento de valores, de atitudes e de normas.
\end{abstract}

Palavras-chave: Sarampo. Educação em Saúde. Tipologia Zabala.

\begin{abstract}
This study was motivated by the measles epidemic that occurred in the country, especially in the state and city of São Paulo, due to the antivaccine movement and the reintroduction of the circulating measles virus from travelers from Europe, the U.S. and Venezuelan immigrants. Numerous actions have been implemented by municipal, state and federal governments, but so far there has been no decrease in the incidence of new cases suggesting that these strategies still need to be improved. In this study, health education strategies were evaluated through social networks as a rapid way of transmitting information about infectious diseases and vaccination prevention. The analysis of digital educational materials (cards) published on facebook by the official bodies: National Council of Justice and Ministry of Health, Health Department of the State of São Paulo Health Department of the City of São Paulo, was carried out in five posts chosen among the above-mentioned bodies. This is a qualitative research that follows the method of documentary research according to Lüdke; André, who used as a theoretical framework the typology of content analysis according to Zabala. The results show the predominance of factual learning content that correspond to the knowledge of easily memorized facts, events, situations, data and phenomena. It was also noted that the strategies are regional, which may be associated with the territorial extension of the federation, which seems to indicate the importance of developing attitudinal content learning cards since they favor grouping values, attitudes and norms.
\end{abstract}

Keywords: Measles. Health Education. Zabala Typology.

\section{Introdução}

O sarampo é uma doença infecciosa causada pelo vírus de RNA (ácido ribonucleico) pertencente ao gênero Morbillivirus, da família Paramyxoviridae. Apresenta-se em oito classes de (A-H) e vinte e quatro subclasses conhecidas como genótipos, nome dado ao conjunto do material genético do vírus (A, B1, B2, B3, C1, C2, D1, D2, D3, D4, D5, D6, D7, D8, D9, D10, D11, E, F, G1, G2, G3, H1 e H2), que se referem as variantes do material genético de RNA do vírus do sarampo (MOSS, 2017). No Brasil, a atual epidemia foi identificada pelo Centro de Vigilância Epidemiológica como sendo o genótipo D8 (WHO, 2019) que teria adentrado o país por viajantes vindos da Europa e dos EUA, em função de ser do mesmo genótipo D8 e, também, serem países que vivem o surto (FUJITA et al., 2019; LOPES, 2019).

Trata-se de uma doença contagiosa de fácil proliferação. $\mathrm{O}$ vírus coloniza os pulmões, de forma que sua propagação é pelas vias respiratórias (MOSS, 2017; SES, 2019). Um doente ao tossir libera micropartículas de saliva contaminada e o ocorre o contágio. Após tossir e contaminar os ambientes em que os doentes se encontram, o vírus pode se manter vivo por até duas horas. Estima-se que um único doente pode infectar em média 18 indivíduos (MOSS, 2017). Por se tratar de doença infectocontagiosa, recomenda-se o isolamento 
dos pacientes (SES S. Paulo, 2019). Os principais sintomas são febre alta, dor de cabeça, manchas vermelhas na pele (que surgem primeiro no rosto e se espalham pelo corpo), tosse, coriza e conjuntivite (MOSS, 2017). De acordo com a Organização Pan-americana da Saúde (Opas), a doença é uma das principais causas de morte entre crianças pequenas, mesmo havendo uma vacina segura e eficaz para preveni-la (STEVANIM, 2018; WHO, 2019).

Atualmente se observam modificações epidemiológicas de doenças infecciosas entre famílias de classe média de países industrializados por força de crenças ligadas aos riscos da vacinação (VASCONCELLOS-SILVA, 2015). Este fenômeno antivacinas tem se espalhado globalmente por redes de sites, de blogs e de celebridades de ampla influência desde 1998, quando Andrew Wakefield (WAKEFIED, 1998) publicou um artigo na renomada revista científica The Lancet, que apresentava a tese de que a vacina tríplice viral contra sarampo, caxumba e rubéola poderia ser uma das causas do autismo. Ao ser investigado, Andrew foi forçado a se retratar publicamente, expondo que seu trabalho continha diversos erros, chegando inclusive a perder sua licença profissional, todavia sua tese sobrevive, sobretudo, nas redes sociais estando na origem dos movimentos antivacinas (VASCONCELLOS-SILVA, 2015).

O sarampo, por exemplo, mesmo eliminado nas Américas há pelo menos dez anos, vem apresentando incidência aumentada. Entre os anos de 2013 e 2015, foram notificados mais de mil casos no Brasil, afetando indivíduos adultos (SBIM, 2016). O Centro de Vigilância Epidemiológica "Prof. Alexandre Vranjac" divulgou, em seu boletim epidemiológico, volume I, número 18, Ano 2019, Vigilância Epidemiológica do Sarampo no Estado de São Paulo, Semanas Epidemiológicas 01 a 50 de 2019, (período de 01/09/2019 a 23/11/2019), foram registrados 14.977 casos confirmados de Sarampo no Estado de São Paulo (SES S. Paulo, 2019).

A baixa cobertura vacinal associada com a entrada do vírus via navio, via aeronaves e imigrantes da Venezuela fizeram com que se estabelecesse o surto epidêmico que foi vivenciado atualmente no Brasil e no Estado de São Paulo (STEVANIM, 2018).

Diante deste cenário, houve a necessidade da intervenção de políticas públicas de vacinação e de prevenção do sarampo, a fim de conter a disseminação da doença. Várias ações para imunoprevenção do sarampo e outras doenças infectocontagiosas estão acontecendo para alcançar esta meta no país e, mais especificamente, no Estado de São Paulo (VIEGAS, 2019). As ações podem ser representadas pela divulgação de material educativo em forma de pôster, banner, cartazes, cards, entre outros, em papel ou em forma digital.

Os cards são pedaços interativos de informação apresentados quase sempre em um formato retangular que são postados na web. Assim como cartões de crédito ou cartas de jogos, os cards da web contêm informações resumidas, relevantes e de rápida compreensão. Embora estejam ocorrendo inúmeras ações, ainda não se observou uma diminuição da incidência de novos casos, sugerindo que estas estratégias ainda precisam ser melhoradas (VIEGAS, 2019).

Fica clara a necessidade da Educação em Saúde em todos os níveis para conscientizar os munícipes a respeito da necessidade de prevenção e aumento da cobertura vacinal com o objetivo de desenvolver, no indivíduo, a autonomia e a responsabilidade para adotar estilos saudáveis de vida. Sendo assim, o presente estudo objetivou a análise documental de cards de campanha vacinal contra a sarampo no Estado de São Paulo no ano de 2019. Com este estudo se pretende mostrar o conhecimento como estratégia para adesão a prevenção através da Educação em Saúde com a finalidade de conscientização.

\section{Material e Métodos}

Trata-se de uma pesquisa qualitativa centrada no método da pesquisa documental, segundo Lüdke; André (2013), uma vez que foram analisados documentos retrospectivos e contemporâneos, considerados cientificamente autênticos. Em relação aos documentos contemporâneos foram analisados cinco cards utilizados em posts em rede social, facebook com objetivo de Educação em Saúde informal, apresentados pelos órgãos oficiais (sendo um responsável pela promoção de Educação em Saúde e dois outros responsáveis pela promoção e cuidado com a saúde da população) em âmbito nacional, estadual e municipal.

Sendo assim, para a realização deste estudo, se utilizou como critérios de seleção dos cards, publicações em posts das seguintes instituições oficiais: Conselho Nacional de Justiça e Ministério da Saúde, Secretaria de Saúde do Estado de São Paulo e Secretaria de Saúde do Município de São Paulo com o objetivo de avaliar a divulgação de campanhas educativas em órgãos públicos. Cada órgão possui uma página na rede social facebook e dessa foram retiradas as informações para a análise documental, centrada na tipologia de Zabala (1998), uma vez que se consideram esses cards fontes atuais e seguras de informações.

Desse modo, vale ressaltar que segundo Zabala (1998), os conteúdos de aprendizagem podem ser classificados, conforme a seguinte tipologia: conteúdos factuais, conteúdos conceituais, conteúdos procedimentais e conteúdos atitudinais.

Zabala (1998) explicita os elementos de sua tipologia como se pode observar a seguir:

Por conteúdos factuais se entende o conhecimento de fatos, acontecimentos, situações, dados e fenômenos concretos e singulares: a idade de uma pessoa a conquista de um território, a localização ou a altura de uma montanha, os nomes, os códigos, os axiomas, um fato determinado num determinado momento, etc. [...]

Este tipo de conhecimento se aprende basicamente mediante atividades de cópia mais ou menos literais, a fim de ser integrado nas estruturas de conhecimento, na memória. [...] Os conceitos e princípios são termos abstratos. Os conceitos se referem ao conjunto de fatos, objetos ou símbolos que têm características comuns, e os princípios se referem a mudanças que se produzem num fato, objeto ou situação em relação 
a outros fatos, objetos ou situações e que normalmente descrevem relações de causa-efeito ou correlação. [...] Um conteúdo procedimental - que inclui entre outras coisas as regras, as técnicas, os métodos, as destrezas u habilidades, as estratégias, os procedimentos - é um conjunto de ações ordenadas e com um fim, quer dizer, dirigidas para realização de um objetivo. São conteúdos procedimentais: ler, desenhar, observar, calcular, classificar, traduzir, recortar, saltar, inferir, espetar, etc. [...]
O termo conteúdos atitudinais engloba uma série de conteúdos que por sua vez podemos agrupar em valores, atitudes e normas. [...] (ZABALA, 1998, p. 41- 46).

Para análise dos cards se inicia pela caracterização do conteúdo dos cards, que foi realizado por meio de um questionamento inicial elaborado pelos autores, que são apresentados no Quadro 1.

Quadro 1 - Caracterização do conteúdo do card

\begin{tabular}{|c|c|c|c|c|c|}
\hline & Card 1 & Card 2 & Card 3 & Card 4 & Card 5 \\
\hline $\begin{array}{c}\text { Quem produziu o } \\
\text { material? }\end{array}$ & $\begin{array}{c}\text { Conselho Nacional } \\
\text { de Justiça }\end{array}$ & Ministério de Saúde & $\begin{array}{c}\text { Secretaria de Saúde } \\
\text { da cidade de São } \\
\text { Paulo }\end{array}$ & $\begin{array}{c}\text { Governo do Estado } \\
\text { Secretaria da Saúde }\end{array}$ & Ministério da Saúde \\
\hline $\begin{array}{c}\text { Qual o tema } \\
\text { abordado? }\end{array}$ & Sarampo & Sarampo & Sarampo & Sarampo \\
\hline $\begin{array}{c}\text { O que se pretende } \\
\text { divulgar? }\end{array}$ & $\begin{array}{c}\text { Campanha de } \\
\text { Vacinação contra } \\
\text { Sarampo }\end{array}$ & $\begin{array}{c}\text { Os sintomas do } \\
\text { sarampo }\end{array}$ & $\begin{array}{c}\text { Campanha de } \\
\text { Vacinação contra } \\
\text { Sarampo }\end{array}$ & $\begin{array}{c}\text { Campanha de } \\
\text { Vacinação contra } \\
\text { Sarampo }\end{array}$ & Fake news \\
\hline $\begin{array}{c}\text { O que se pretende } \\
\text { transmitir? }\end{array}$ & $\begin{array}{c}\text { A importância } \\
\text { da Prevenção } \\
\text { (Vacinação) }\end{array}$ & $\begin{array}{c}\text { Conhecimentos } \\
\text { sobre os sintomas }\end{array}$ & $\begin{array}{c}\text { Necessidade de } \\
\text { vacinação }\end{array}$ & $\begin{array}{c}\text { A importância } \\
\text { da Prevenção } \\
\text { (Vacinação) }\end{array}$ & $\begin{array}{c}\text { Cuidados com as } \\
\text { Fake news }\end{array}$ \\
\hline $\begin{array}{c}\text { Para quem é } \\
\text { destinada a } \\
\text { mensagem? }\end{array}$ & $\begin{array}{c}\text { A toda federação } \\
\text { A toda federação }\end{array}$ & $\begin{array}{c}\text { Aos grupos } \\
\text { prioritários. }\end{array}$ & $\begin{array}{c}\text { Aos munícipes das } \\
\text { cidades abrangidas } \\
\text { pela campanha. }\end{array}$ & A toda federação \\
\hline
\end{tabular}

Fonte: Os autores.

Após essa caraterização, foi aplicada a tipologia de Zabala (1998) para cada um dos cinco cards escolhidos. Para a análise foi relacionado cada enunciado, figura e imagem com uma das quatro tipologias introduzidas por Zabala (1998).

Além disso, apresenta-se um estudo comparado entre os diferentes cards, mostrando as diferenças de conteúdos de aprendizagem entre os cards analisados.

\section{Resultados e Discussão}

Foram selecionados cinco cards de posts publicados em rede social facebook de órgãos: Federal - Conselho Nacional de Justiça e Ministério da Saúde; Estadual - Secretaria de Saúde do Estado de São Paulo; Municipal - Secretaria de Saúde do Município de São Paulo. O primeiro âmbito de análise e de caracterização dos conteúdos dos cards foi sumarizado no Quadro 1.

A seguir serão descritos os conteúdos de aprendizagem de cada card individual, de acordo com a tipologia de Zabala (1998).

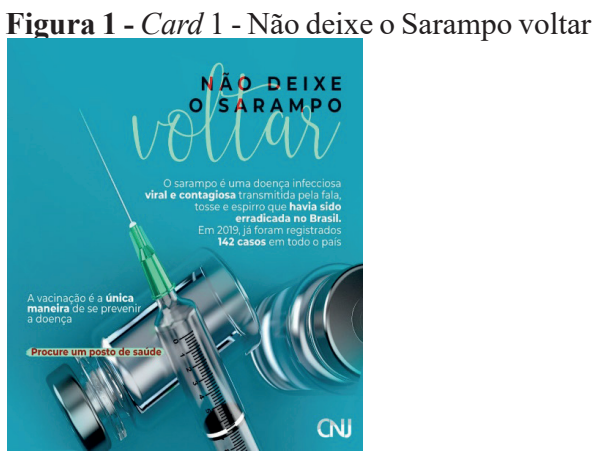

Fonte: Disponível em: < https://www.facebook.com/ cnj.oficial/ $>$.

Quadro 2 - Relação conforme Zabala (1998)

\begin{tabular}{|l|l|}
\hline \multicolumn{1}{|c|}{ Enunciado } & \multicolumn{1}{c|}{ Classificação } \\
\hline Não deixe o sarampo voltar & Atitudinais \\
\hline $\begin{array}{l}\text { O sarampo é uma doença infecciosa, } \\
\text { viral e contagiosa transmitida pela } \\
\text { fala, tosse e espirro que havia sido } \\
\text { erradicada no Brasil. Em 2019, já } \\
\text { foram registrados 142 casos em todo } \\
\text { país. }\end{array}$ & Factuais e conceituais \\
\hline $\begin{array}{l}\text { Vacinação é a única maneira de se } \\
\text { prevenir a doença. }\end{array}$ & $\begin{array}{l}\text { Conceitual e } \\
\text { procedimental e factual }\end{array}$ \\
\hline Procure um Posto de Saúde & $\begin{array}{l}\text { Procedimental e } \\
\text { atitudinal }\end{array}$ \\
\hline Imagens e figuras & $\begin{array}{l}\text { Conceituais, } \\
\text { procedimental e factual }\end{array}$ \\
\hline
\end{tabular}

Fonte: Os autores.

Dentro da classificação, segundo tipologia Zabala (1998), encontra-se neste card 1 as quatro classificações.

No enunciado: Não deixe o sarampo voltar", classifica-se como atitudinais, em que a fala remete a uma atitude que pode impedir a volta da doença. No enunciado: "O sarampo é uma doença infecciosa, viral e contagiosa transmitida pela fala, tosse e espirro e que havia sido erradicada no Brasil. Em 2019, já foram registrados 142 casos em todo país", tem-se a classificação factual e conceitual, na qual se lê "que havia sido erradicada do Brasil", tem-se um fato, no qual se lê: “Em 2019, já foram registrados 142 casos em todo país", temse um dado factual, trata-se de fato também e no qual se lê: "O sarampo é uma doença infecciosa, viral e contagiosa transmitida pela fala, tosse e espirro", trata-se de conteúdo conceitual. No texto identifica-se ainda: "Vacinação é a única maneira de se prevenir a doença", identificando-se segundo 
classificação Zabala como conceitual, procedimental e factual, em função da vacina ser cientificamente comprovada como forma de prevenção, procedimental em que remete a ideia de haver apenas esta forma de prevenção. Identifica-se também neste card a presença de imagens e figuras que mostram a seringa e o frasco de vacina: classificando-se como conceituais e procedimental em decorrência de a vacina ser a única forma de prevenção da doença, conforme já explicitado acima.

Figura 2- Card 2 - Conheça os sintomas do sarampo

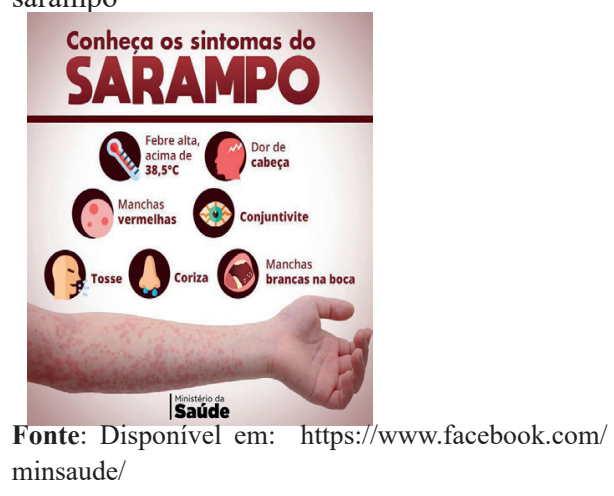

Quadro 3 - Relação conforme Zabala

\begin{tabular}{|l|l|}
\hline \multicolumn{1}{|c|}{ Enunciado } & \multicolumn{1}{c|}{ Classificação } \\
\hline Conheça os sintomas do sarampo & Conceitual \\
\hline Febre alta acima dos $38,5^{\circ}$ & Factual e conceitual \\
\hline Dor de cabeça & Factual e conceitual \\
\hline Manchas vermelhas & Factual e conceitual \\
\hline Conjuntivite & Factual e conceitual \\
\hline Tosse & Factual e conceitual \\
\hline Coriza & Factual e conceitual \\
\hline Manchas brancas na boca & Factual e conceitual \\
\hline Imagens e figuras & Conceituais \\
\hline
\end{tabular}

Fonte: Os autores.

O card 2 apresenta, segundo tipologia Zabala, de informações conceituais nas quais se chama os leitores a conhecer os sintomas no enunciado: "Conheça os sintomas do sarampo", em que se utilizou caixa alta e destacou o nome da doença: "Sarampo". Este card apresenta ainda dados classificados, segundo tipologia Zabala, em factuais e conceituais ao enumerar os sintomas de forma clara com utilização de imagens identificadas: "febre alta acima dos $38,5{ }^{\circ} \mathrm{C}$, dor de cabeça, manchas vermelhas, conjuntivites, tosse, coriza e manchas brancas na boca".

Figura 3 - Card 3 - Campanha de vacinação contra o sarampo

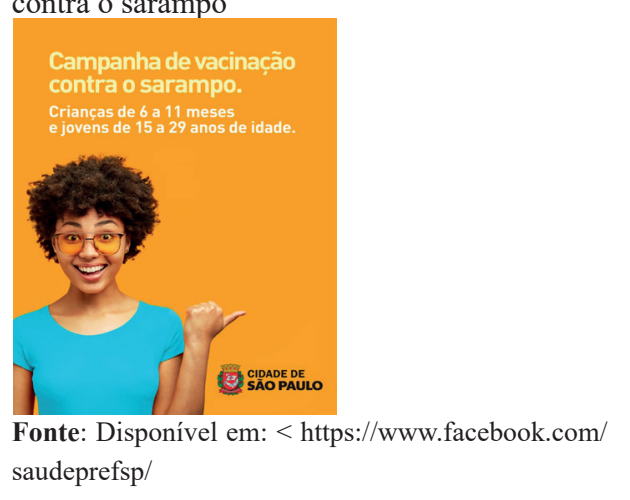

Quadro 4 - Relação conforme Zabala

\begin{tabular}{|l|l|}
\hline Enunciado & Classificação \\
\hline Campanha de vacinação contra o sarampo & Procedimental \\
\hline $\begin{array}{l}\text { Crianças de } 6 \text { a } 11 \text { meses e jovens de } 15 \text { a } 29 \\
\text { anos de idade. }\end{array}$ & Factual \\
\hline Imagens e figuras & Conceituais \\
\hline
\end{tabular}

Fonte: Os autores.

O card 3 utiliza caixa alta no título e, segundo tipologia Zabala, classifica-se o conteúdo como procedimental. Compreende-se ainda que atinge plenamente seu objetivo: informar a campanha de vacinação. No texto: Crianças de 6 a 11 meses e jovens de 15 a 29 anos de idade, o card identifica de forma clara o público-alvo, ou seja, a faixa etária que deverá ser vacinada nesta campanha. Identifica-se como conteúdo factual.

Figura 4 - Card 4 - Campanha de vacinação

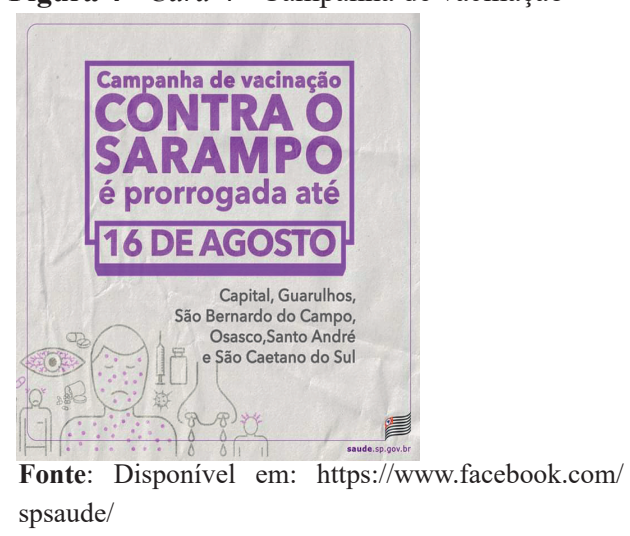

Quadro 5 - Relação conforme Zabala

\begin{tabular}{|l|l|}
\hline \multicolumn{1}{|c|}{ Enunciado } & Classificação \\
\hline $\begin{array}{l}\text { Campanha de Vacinação contra o Sarampo é } \\
\text { prorrogada até 16 de agosto }\end{array}$ & Procedimental \\
\hline $\begin{array}{l}\text { Capital, Guarulhos, São Bernardo do Campo, } \\
\text { Osasco, Santo André e São Caetano do Sul }\end{array}$ & Procedimental \\
\hline Imagens e figuras & Conceituais \\
\hline
\end{tabular}

Fonte: Os autores.

Os enunciados textuais e as imagens e figuras foram classificados em conteúdos factuais. Esta análise mostrou que o card 4 traz o seguinte enunciado: Campanha de vacinação contra o Sarampo é prorrogada até dia 16 de agosto. Notase a utilização de caixa alta, em cor chamativa, induzindo os leitores a memorizarem o conteúdo. O card é composto de página única, no formato figura e foi utilizado para divulgação na rede social da Secretaria de Saúde do Estado de São Paulo. A análise dos conteúdos procedimentais do card mostrou que a linguagem adotada para comunicação é de fácil entendimento e atinge o objetivo pretendido: divulgar a campanha de vacinação contra sarampo. O card incentiva a campanha de vacinação, divulga a região abrangida e até qual a data em que será realizada. $\mathrm{O}$ material educativo apresenta o conceito em forma de figuras e de imagens, que trazem os conceitos da doença evidenciando a imagem do vírus e o conceito de prevenção e de vacinação, através do frasco da vacina e da seringa, e o conceito de sinais e sintomas clínicos 
da doença do sarampo, mostrando manchas no corpo, coriza, conjuntivite, dor de cabeça, bem como o tratamento pela imagem de frascos e dos comprimidos. O conteúdo atitudinal, através da leitura e imagens do card, se encontra de forma subjetiva. A informação de conscientizar da importância e relevância das pessoas irem se vacinar não está clara.

Figura 5 - Card 5 - Isto é fake news!

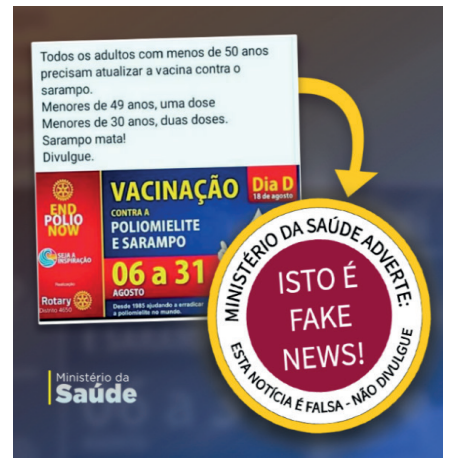

Fonte: Disponível em: < https://www.facebook.com/ minsaude

Quadro 6 - Relação conforme Zabala

\begin{tabular}{|l|l|}
\hline \multicolumn{1}{|c|}{ Enunciado } & Classificação \\
\hline $\begin{array}{l}\text { Ministério da Saúde adverte: esta notícia é } \\
\text { falsa - não divulgue }\end{array}$ & Factual \\
\hline Isto é fake News! & Factual \\
\hline Imagens e figuras & Conceituais \\
\hline
\end{tabular}

Fonte: Os autores.

O card 5 divulgado, em rede social facebook, foi utilizado um card verdadeiro publicado no ano de 2018 e replicado em 2019 como se a campanha estivesse vigente neste período. Tornou-se muito frequente a divulgação das chamadas "Fake News" nas redes sociais. Não foi identificado se de forma consciente ou inconsciente, todavia, esse tipo de publicação presta um grande desserviço à sociedade, de forma geral, e esta foi trazida para este trabalho com a finalidade de ressaltar a importância de verificar a fonte de informação e não receber publicações e simplesmente replicá-las. Segundo tipologia Zabala, classificam-se como factuais em função de "Fake News" retratarem o conhecimento de fatos, apesar de serem inverdades. Neste card, o Ministério da Saúde ressalta que se trata de "Fake News".

A frequência de cada tipologia utilizada nos cards, Conselho Nacional de Justiça (card 1), Ministério da Saúde (card 2), Secretaria de Saúde da Cidade de São Paulo (card 3), Secretaria de Saúde do Estado de São Paulo (card 4) e Ministério da Saúde (card 5), está representada no gráfico da Figura 6.
Figura 6 - Frequência e distribuição das tipologias de acordo com Zabala (1998) no material educativo de cinco cards publicados na rede social facebook

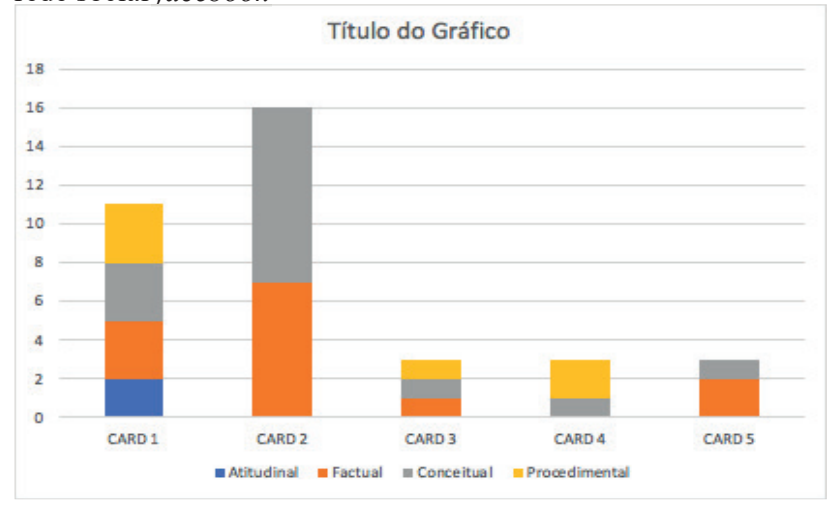

Fonte: Dados da pesquisa.

Os resultados mostram que o único card que apresentou tipologia atitudinal foi o número 1 do Conselho Nacional de Justiça (Figura 6). Segundo Zabala, a tipologia atitudinal é aquela que relaciona o ser com valores, normas e atitudes. Portanto, o estudo mostra que as campanhas possuem deficiências em transformar a atitude dos indivíduos com o tema Sarampo. A conscientização é o primeiro passo para a transformação.

A maioria dos cards utilizou a tipologia factual para transmitir a informação das campanhas de prevenção contra o Sarampo (Figura 6). Este estudo concluiu a predominância de conteúdos de aprendizagem factuais, em que se entende o conhecimento de fatos, acontecimentos, situações, dados e fenômenos concretos e singulares. Em outras palavras, considera-se que um indivíduo aprendeu um conteúdo factual, quando é capaz de reproduzi-lo. Esse tipo de material transmite a informação através da memorização. Somente o card 5 do Governo do Estado de São Paulo e Secretaria da Saúde não utilizou essa tipologia.

Três dos cinco cards utilizaram a tipologia conceitual e procedimental em sua divulgação (Figura 6). Os órgãos federais (Conselho Nacional de Justiça e Ministério da Saúde), estadual (Secretaria de Saúde do Governo do Estado de São Paulo) e municipal (Secretaria da Saúde do Município de São Paulo), mostram uma preocupação na transmissão das informações através de estabelecimento de causa e efeito e promoção de ações ordenadas para prevenção do Sarampo.

O card "fake News" utilizou somente a tipologia factual, através da memorização, para transmitir a informação de campanhas falsas (Figura 6).

Nos cinco cards foi possível identificar a promoção da Educação em Saúde utilizando as redes sociais como forma de disseminação de informações sobre a doença, meios de prevenção, ressaltando ser a vacina o meio seguro de se proteger, promovendo as campanhas de vacinação, informando as faixas etárias para quais as campanhas abrangem e as regiões em que as campanhas seriam promovidas. Os cards em posts de facebook são formas rápidas de levar informações 
para grandes números de usuários, com destaque para o público mais jovem com utilização de figuras, de imagens, de cores e de palavras em caixa alta com propósito de ressaltar a relevância das campanhas educativas. Todavia, não se pode deixar de mencionar a grande incidência das chamadas "fake news" como mostrado no card 5, como desserviço à Educação em Saúde, promovendo notícias falsas e induzindo o leitor a desinformação. Destaca-se a relevância de averiguar as fontes de informação. Os cards, contidos neste estudo, foram retirados de órgãos oficiais em função de grande quantidade de inverdades produzidas na área da saúde pelas redes sociais.

\section{Conclusão}

A análise da incidência dos conteúdos de aprendizagem, segundo tipologia Zabala, identificou a predominância dos conteúdos de aprendizagem classificados como factuais, que favorecem a memorização e se sugere a elaboração de cards com predominância de conteúdos de aprendizagem, classificados como atitudinais que indicam a conscientização.

Observou-se que as estratégias são regionais o que pode ser explicado pela enorme extensão territorial da federação e características próprias, que dificultam ou facilitam as campanhas de vacinação.

Compreende-se que a Educação em Saúde deve ser articulada entre os órgãos federais, estaduais e municipais de saúde e educação, favorecendo a prevenção através da conscientização.

\section{Referências}

FUJITA, D.M. et al. Routine vaccination for travelers from emerging countries: epidemiological profile of a public travel medicine clinic in Sao Paulo/Brazil. Int. J. Travel Med. Global Health, v.7, p.13-17, 2019.

LOPES, M.H. Vírus do sarampo de surto em SP é de mesmo grupo prevalente na Europa. Jornal USP. Ciências da Saúde. 2019. Disponível em: https://jornal.usp.br/ciencias/cienciasda-saude/virus-do-sarampo-de-surto-em-sp-e-de-mesmo-grupoprevalente-na-europa/.

LUDKE, M.; ANDRE, M.E.D.A. Métodos de coleta de dados: observação, entrevista e análise documental. In: LUDKE, M.; ANDRE, M.E.D.A. Pesquisa em Educação: abordagens qualitativas. São Paulo: EPU, 1986. p.25-38.

MOSS WJ. Measles. Lancet, v.390, n.10111, p.2490-2502, 2017. doi: 10.1016/S0140-6736(17)31463-0.

SBIM. Sociedade Brasileira de Imunizações. Calendários de vacinação: pacientes especiais 2019-2020. São Paulo: Sociedade Brasileira de Imunizações, 2016.

SES S. Paulo. Centro de Vigilância Epidemiológica- CVE. Governo do Estado de São Paulo. Secretaria de Estado da Saúde. Sarampo Alerta. 2019. Disponível em: <http://portal.saude. sp.gov.br/resources/cve-centro-de-vigilancia-epidemiologica/ areas-de-vigilancia/doencas-de-transmissao-respiratoria/ sindrome-da-rubeola-congenita-src/doc/2019/sarampo 19 rubeola_medida_controle.pdf $>$. Acesso em: $20 \mathrm{dez} .2019$.

SES S. Paulo. Centro de Vigilância Epidemiológica- CVE. Governo do Estado de São Paulo. Secretaria de Estado da Saúde. Sarampo Boletim Epidemiológico. 2019. Disponível em: < http://www.saude.sp.gov.br/resources/cve-centro-de-vigilanciaepidemiologica/areas-de-vigilancia/doencas-de-transmissaorespiratoria/sindrome-da-rubeola-congenita-src/doc/2019/ sarampo19_18bolepid1712.pdf>. Acesso em: 20 dez. 2019.

STEVANIM, L.M. Sarampo de volta ao mapa. RADIS Comunicação e Saúde. Fiocruz. Fundação Oswaldo Cruz. RADIS 191, 2018. Disponível em: https://radis.ensp.fiocruz.br/ index.php/home/reportagem/sarampo-de-volta-ao-mapa. Acesso em 12 jul. 2019.

VASCONCELLOS-SILVA, P.R.; CASTIEL, L.D.; GRIEP, R.H. A sociedade de risco midiatizada, o movimento antivacinação e o risco do autismo. Ciênc. Saúde Coletiva, v.20, n.2, p.607-616, 2015.

VIEGAS, S.M.F. et al. A vacinação e o saber do adolescente: educação em saúde e ações para a imunoprevenção. Ciênc. Saúde Coletiva, v.24, n.2, p.351-360, 2019.

WAKEFIELD, A.J. et al. Ileal-lymphoid-nodular hyperplasia, non-specific colitis, and pervasive developmental disorder in children. Lancet, v.351, n.9103, p.637-641, 1998.

WHO - World Health Organization. Weekly epidemiological record. Genetic characterization of measles and rubella viruses detected through surveillance for global measles and rubella elimination, 2016-2018. Genebra: WHO, 2019.

WHO - World Health Organization. Weekly epidemiological record. Global Advisory Committee on Vaccine Safety. Genebra: WHO, 2019.

ZABALA, A. A prática educativa, como ensinar. Porto Alegre: Artmed, 2010. 